\title{
Repression of Toll-like receptor-4 by microRNA- 149-3p is associated with smoking-related COPD
}

\author{
This article was published in the following Dove Press journal: \\ International Journal of COPD \\ 22 February 2017 \\ Number of times this article has been viewed
}

\author{
Wen Shen ${ }^{1, *}$ \\ Jia Liu',* \\ Guohou Zhao' \\ Minjuan Fan' \\ Gao Song ${ }^{3}$ \\ Yang Zhang' \\ Zhiying Weng ${ }^{3}$ \\ You Zhang ${ }^{4}$ \\ 'Department of Respiratory Medicine, \\ ${ }^{2}$ Department of Experimental \\ Zoology, The Second Affiliated \\ Hospital of Kunming Medical \\ University, ${ }^{3}$ School of Pharmaceutical \\ Science, Kunming Medical University, \\ ${ }^{4}$ Department of Hematology, The \\ Second Affiliated Hospital of Kunming \\ Medical University, Kunming, Yunnan \\ Province, People's Republic of China \\ *These authors contributed equally \\ to this work
}

Background: Smoking is the leading cause of COPD. Exploring molecular markers and understanding the pathogenic mechanisms of smoking-related COPD are helpful for early clinical diagnosis and treatment of the disease. This study aims to identify specific circulating microRNAs (miRNAs) from the blood of COPD patients with a long history of smoking.

Methods: Blood samples from four different groups were collected, and miRNA microarray was performed. Differential expression of miRNAs was verified by quantitative polymerase chain reaction. In vitro, THP-1 cells were cultured and stimulated with cigarette smoke extract (CSE) or transfected with miR-149-3p inhibitor/mimics. Protein levels of Toll-like receptor 4 (TLR-4) and nuclear factor $\kappa \mathrm{B}(\mathrm{NF}-\mathrm{\kappa B})$ were detected using Western blot and immunofluorescence. Interleukin (IL)- $1 \beta$ and tumor necrosis factor (TNF)- $\alpha$ levels were determined by an enzyme-linked immunosorbent assay.

Results: miRNA profiling revealed that the expression of 56 miRNAs was changed between the four groups. Expression of miR-149-3p in group C (non-smoker non-COPD) was higher than in group S (smoker non-COPD), S-COPD (smoker with stable COPD) and AE-COPD (smoker with acute exacerbation COPD). CSE stimulation down-regulated the expression of miR-149-3p and up-regulated the TLR-4 and NF- $\mathrm{kB}$ levels in THP-1 cells. Transfecting miR149-3p inhibitors in THP-1 cells also increased the expression of its target genes. Furthermore, overexpression of miR-149-3p inhibited the TLR-4/NF- $\mathrm{KB}$ signaling pathways and reduced the secretion of IL-1 $\beta$ and TNF- $\alpha$.

Conclusion: This study found that smoking can induce differential expression of circulating miRNAs, such as down-regulation of miR-149-3p. Reducing miR-149-3p may increase the inflammatory response in COPD patients through the regulation of the TLR-4/NF- $\kappa B$ signaling pathway.

Keywords: smoking, COPD, microRNA-149-3p, Toll-like receptor 4, nuclear factor $\mathrm{\kappa B}$

\section{Introduction}

COPD is a major cause of illness and death worldwide. ${ }^{1}$ According to the World Health Organization (WHO), 3 million people in the world die as a consequence of COPD every year. ${ }^{2}$ COPD involves chronic inflammation of the lungs, particularly in the peripheral airways and parenchyma, which increases during periods of acute exacerbation. It is also associated with systemic inflammation, which may contribute to or worsen several comorbidities and may be derived from the "spill-over" of inflammatory mediators from the peripheral lungs. ${ }^{3}$ The development of COPD is multifactorial, and the risk factors are both genetic and environmental. ${ }^{4}$ Even though traffic and other outdoor pollution, secondhand smoke (SHS), biomass smoke and dietary factors are all associated with COPD, cigarette smoking is regarded as one of the most important contributors to COPD. ${ }^{5}$

Increasing evidence showing that smoking is a cause of COPD has been growing for $>40$ years and has been extensively reviewed in three US Surgeon General's 
Reports. ${ }^{6-8}$ The estimated fraction of COPD mortality attributable to smoking was 54\% for men 30-69 years of age and $52 \%$ for men 70 years of age or older. ${ }^{9}$ Exposure to SHS, which contains potent respiratory irritants, also leads to chronic airway inflammation and obstruction. A study from the People's Republic of China found that self-reported cumulative lifetime SHS exposure at home and work was related to a greater risk of COPD, as defined by spirometry (Global initiative for chronic Obstructive Lung Disease [GOLD] stage 1 or greater). ${ }^{10}$ Another study showed that living with a smoker was associated with a greater risk for COPD. ${ }^{11}$

MicroRNAs (miRNAs) are small non-coding RNA molecules that modulate the levels of specific genes and proteins. ${ }^{12}$ Identifying the expression patterns of miRNAs in COPD may enhance our understanding of the mechanisms underlying COPD. Several studies have investigated the effects of cigarette smoke on miRNA expression. ${ }^{13,14}$ A total of 70 miRNAs and 2,667 messenger RNAs (mRNAs) were differentially expressed from lung tissues obtained from patients with COPD and smokers without COPD ${ }^{15}$ In recent years, mechanisms of many miRNAs related to COPD, such as miR-145, ${ }^{16,17}$ miR-146a, ${ }^{18}$ miR-106b ${ }^{19}$ and miR-223, ${ }^{20}$ have been reported. This study also found that 140 miRNAs that were derived from COPD patients and compared to healthy controls were significant and 14 miRNAs that were derived from patients with lung cancer and compared to COPD patients were significant. ${ }^{21}$ It is important to discover more candidate markers to distinguish between the different stages or severity in COPD patients for diagnosis and treatment. However, miRNAs caused by smoking in COPD patients still need further research. Circulating miRNAs as stable blood-based markers can be applied to cancer detection, ${ }^{22-24}$ coronary artery disease detection, ${ }^{25}$ liver injury evaluation ${ }^{26}$ and COPD diagnosis. ${ }^{27}$ Several studies found that skeletal muscle-specific miRNAs can be detected in the blood of COPD patients. ${ }^{28,29}$ In addition, another study reported that genotypes of miR-149 were associated with the overall survival of lung cancer patients. ${ }^{30}$ To explore differentially expressed circulating miRNAs caused by smoking in CODP patients, we collected blood samples of smokingrelated COPD patients at different stages of the disease and performed miRNA microarray. Finally, we chose one of the differentially expressed miRNAs, miR-149-3p, and studied its mechanism through further in vitro experiments.

\section{Materials and methods}

\section{Ethics statement}

The use of human blood samples for this study was approved by the Medical Ethics Committee of The Second Affiliated
Hospital of Kunming Medical University. Written consent was received from all participants in this study at the time of sample collection.

\section{Clinical samples}

Blood samples from four groups of patients were collected at The Second Affiliated Hospital of Kunming Medical University and stored in liquid nitrogen for further use. Each of the four groups contained 20 blood samples: as control, nonsmoker non-COPD (group C); smoker non-COPD (group S); smoker with stable COPD (group S-COPD); smoker with acute exacerbation COPD (group AE-COPD).

\section{Cell culture and transient transfection}

The murine monocytic cell line THP-1 (ATCC, Rockville, MD, USA) was cultured by Dulbecco's Modified Eagle's Medium (DMEM) supplemented with 10\% fetal bovine serum, $2 \mathrm{mM} / \mathrm{L}$ glutamine, 100 units $/ \mathrm{mL}$ penicillin and $0.1 \mathrm{mg} / \mathrm{mL}$ streptomycin, in a humidified incubator $\left(5 \% \mathrm{CO}_{2}\right.$ in air) at $37^{\circ} \mathrm{C}$. Cigarette smoke extract (CSE) was prepared by a method modified from a previously described protocol. ${ }^{31}$ Briefly, one cigarette was bubbled through $25 \mathrm{~mL}$ of DMEM at a constant rate, and this solution was considered as $100 \%$ concentration of CSE. The 100\% CSE was freshly generated for each experiment and diluted to a final working concentration (10\%) and used within $30 \mathrm{~min}$. To analyze the effect of miR-149-3p, cells were passed into six-well plates $\left(3 \times 10^{7}\right.$ cells/plate $)$, and after $\sim 24 \mathrm{~h}$ at $37^{\circ} \mathrm{C}$, they were transfected with miR-149-3p mimics, inhibitors or negative control (NC) with Lipofectamine 2000. Subsequent processing was completed according to the study protocol.

\section{RNA extraction and miRNA microarray}

Trizol (Thermo Fisher Scientific, Waltham, MA, USA) was used to extract the total RNAs from blood samples or cells. Then mirVana miRNA Isolation Kit (Ambion, Austin, TX, USA) was used to purify small RNAs in accordance with the manufacturer's protocol. The concentration and purity of RNAs were determined by optical density 260/280 readings using spectrophotometer (NanoDrop ND-2000). By using the RNA 6000 Nano Lab-on-a-Chip kit and the Bioanalyzer 2100 (Agilent Technologies, Santa Clara, CA, USA), RNA integrity was determined by electrophoresis.

Microarray assay was performed by KangchengBio Corporation, Shanghai, the People's Republic of China. The RNA extract from six blood samples in each group was used for microassay analysis by miRCURY LNA ${ }^{\mathrm{TM}}$ microRNA 
Array according to the manufacturer's instruction. Threshold values of $\geq 1.5$ - and $\leq-1.5$-fold change were used to identify the differentially expressed genes. The data were $\log 2$ transformed and median centered by genes using the Adjust Data function of Mev (Multiexperiment Viewer) software (DanaFarber Cancer Institute, Boston, MA, USA) and then further analyzed with hierarchical clustering with average linkage.

\section{Quantitative polymerase chain reaction (qPCR) analysis}

Total RNAs of 60 blood samples ( 20 in each group) and cells under different treatments were isolated and purified. The samples with OD260/280 ratio >1.8 were reversely transcribed using a GoScropt ${ }^{\mathrm{TM}}$ Reverse Transcription System Kit (Promega, Madison, WI, USA) according to the manufacturer's instructions. The expressions of selected miRNA were analyzed using $\mathrm{qPCR}$ with a Go Taq ${ }^{\circledR} \mathrm{qPCR}$ Master Mix kit (Promega) on StepOne Plus PCR System (Applied Biosystems, Carlsbad, CA, USA). glyceraldehyde-3-phosphate dehydrogenase (GAPDH) was used as an internal control, and $2^{-\Delta \Delta C T}$ method was used to calculate the expression of miRNA. The primers for qPCR analysis are given in Table 1.

\section{Western blot}

Cells were lysed in radio-immunoprecipitation assay buffer. Protein concentrations were determined using the BCA Protein Assay Kit (Thermo Fisher Scientific). Protein samples were boiled, then separated on polyacrylamide gels and transferred to polyvinylidene fluoride membrane (EMD Millipore, Billerica, MA, USA). Membranes were incubated overnight at $4{ }^{\circ} \mathrm{C}$ with anti-Toll-like receptor 4 (TLR-4) (Abcam; diluted 1:500) and anti-nuclear factor $\kappa \mathrm{B}(\mathrm{NF}-\kappa \mathrm{B})$ p65 (Abcam; diluted 1:5,000), or anti-GAPDH antibody (Abcam; diluted 1:5,000). GAPDH was used as an internal

Table I Primers information for PCR used in this study

\begin{tabular}{ll}
\hline ID & Sequence (5' -3') $^{\prime}$ \\
\hline$\beta$-actin F & CATTGCTGACAGGATGCAGA \\
$\beta$-actin R & CTGCTGGAAGGTGGACAGTGA \\
TLR-4 F & CGCTCTGGCATCATCTTCAT \\
TLR-4 R & TGCTCAGGATTCGAGGCTTT \\
U6 F & CTCGCTTCGGCAGCACA \\
U6 R & AACGCTTCACGAATTTGCGT \\
miR-149-3p & AGGGAGGGACGGGGGCTGTGC \\
miR-149-3p RT & CTCAACTGGTGTCGTGGAGTCG \\
miR-149-3p F & GCAATTCAGTTGAGGCACAG \\
miR-149-3p R & ACACTCCAGCTGGGAGGGAGGG \\
\hline
\end{tabular}

Abbreviations: F, forward; PCR, polymerase chain reaction; R, reverse; TLR-4, Toll-like receptor-4. control. After washing with Tris- $\mathrm{HCl}$ Tween buffer solution, the blots were incubated with a horseradish peroxidase (HRP)-conjugated secondary antibody (Santa Cruz; diluted 1:2,000) at room temperature for $1 \mathrm{~h}$. The blots were visualized by Pierce ECL Plus Western Blotting Substrate (Pierce) following the manufacturer's instructions. Immunoreactive bands were detected with enhanced chemiluminescent HRP substrate (Millipore).

\section{Immunofluorescence}

Cells were fixed with 4\% paraformaldehyde solution for $20 \mathrm{~min}$ at room temperature and then washed with phosphatebuffered saline (PBS). Triton X-100 (0.5\%) in PBS was used for permeabilization of cells. Then, the cells were blocked with $10 \%$ fetal calf serum (FCS) for $1 \mathrm{~h}$ at room temperature and incubated with anti-TLR-4 (Abcam; diluted 1:200) and anti-NF- $\kappa$ B p65 (Abcam; diluted 1:500) overnight at $4^{\circ} \mathrm{C}$. After washing with PBS, the cells were incubated with secondary antibody. Nuclei were counterstained with 4',6-diamidino-2-phenylindole for $5 \mathrm{~min}$ at room temperature. Images of the staining were taken with a fluorescence microscope (Thermo Fisher Scientific).

\section{Enzyme-linked immunosorbent assay (ELISA)}

Levels of tumor necrosis factor- $\alpha$ (TNF- $\alpha)$ and interleukin (IL) $-1 \beta$ in treated cells were measured using an antigen-based sandwich ELISA. Mouse TNF- $\alpha$ ELISA Kit (Elabscience, E-EL-M0037c) and Mouse IL-1 $\beta$ ELISA Kit (Elabscience, E-EL-M0049c) were used, and the absorbance was measured at $450 \mathrm{~nm}$ using a microplate spectrophotometer (Thermo, Multiskan GO).

\section{Statistical analysis}

Data of miRNAs expression from the four groups were analyzed using Bonferroni's multiple comparison test. Differences between groups in in vivo experiment were determined by an unpaired Student's $t$-test method using the Prism (GraphPad Software Inc., La Jolla, CA, USA). A $P$-value $<0.05$ was considered to be statistically significant.

\section{Results}

Smoking-induced different expression levels of miRNAs including downregulation of $\mathrm{miR}-\mathrm{I} 49-3 \mathrm{p}$

To explore differentially expressed circulating miRNAs caused by smoking in COPD patients, we collected blood samples from group $\mathrm{C}, \mathrm{S}, \mathrm{S}-\mathrm{COPD}$ and AE-COPD. We performed total RNA extraction and miRNA microarray. 
Among 689 types of human miRs that could be detected by the probes, the expression levels of 56 miRNAs were changed between the four groups (Figure 1A). Based on the data of fold changing (unpublished data), six members, including miR3202, miR-26a-5p, miR-451b, miR-96-5p, miR-301a-5p and miR-149-3p, were selected for qPCR validation. We observed that miR-3202, miR-26a-5p, miR-451b and miR-149-3p, were down-regulated in the S, S-COPD and AE-COPD groups. miR-96-5p was reduced in the blood samples of group $\mathrm{S}$ compared to group $\mathrm{C}$, while in the S-COPD and AE-COPD groups, it showed significantly higher expression. Besides,
miR-301a-5p exhibited low expression levels only in COPD smokers with acute exacerbation period (Figure 1B).

\section{Decreasing miR-|49-3p caused up- regulation of TLR-4 in THP-I cells stimulated by CSE}

As miR-149-3p was down-regulated in the three smoking groups, we performed CSE stimulation treatment on the THP-1 cell line. Concentration of IL- $1 \beta$ and TNF- $\alpha$ was significantly increased in the CSE group compared with the NC group (Figure 2A). qPCR results show that miR-149-3p
A
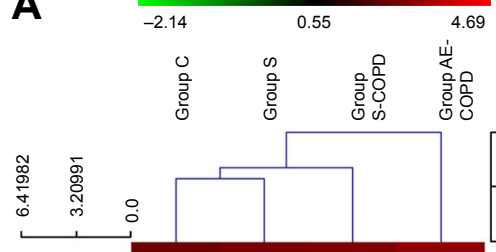

5.1723537

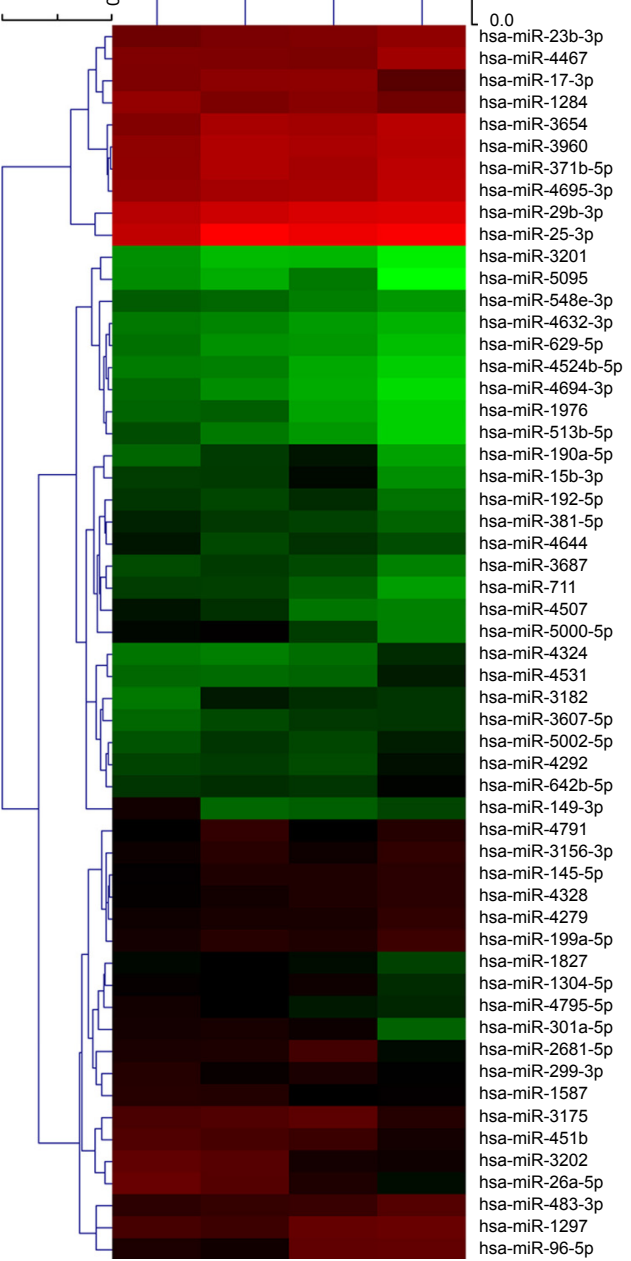

B
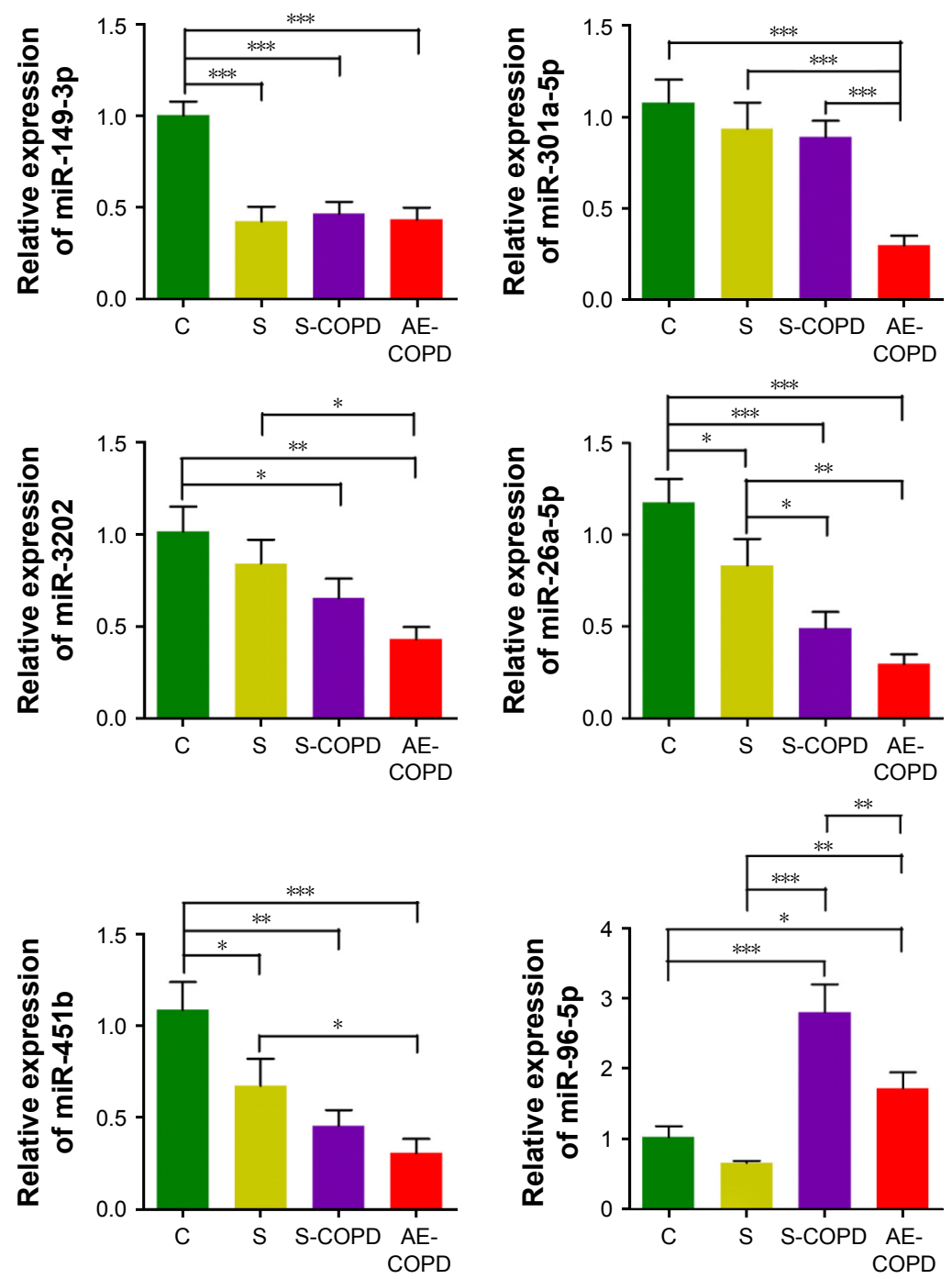
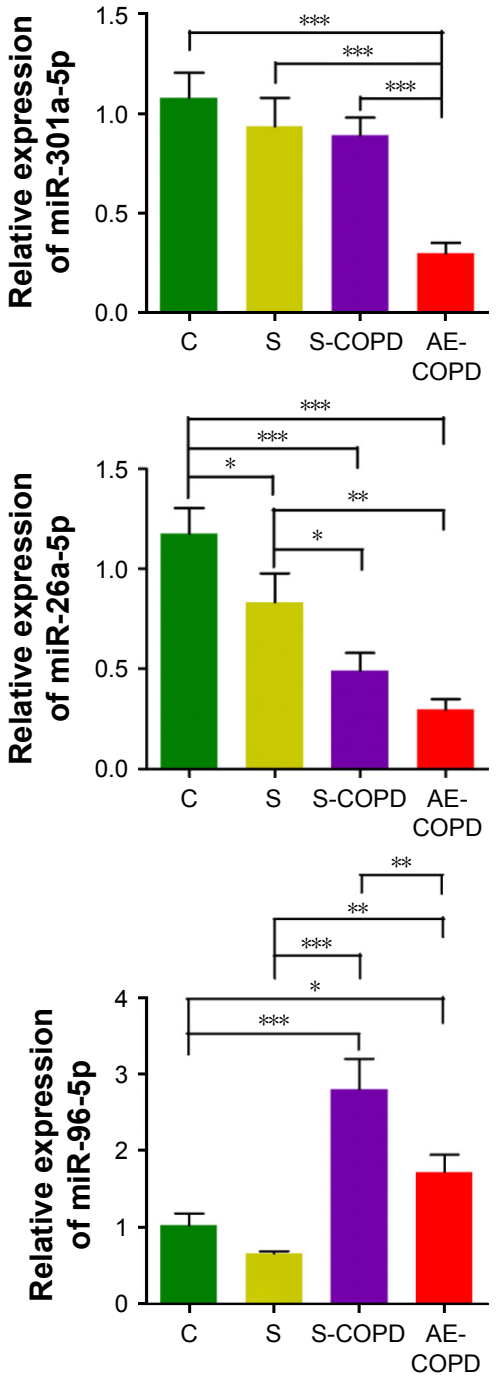

Figure I Differentially expressed miRNAs among group C (non-smoker non-COPD), group S (smoker without COPD), group S-COPD (smoker with stable COPD) and group AE-COPD (smoker with acute exacerbation COPD). (A) MicroRNAs microarray representing the expression levels of 56 miRNAs were changed between the four groups ( $\mathrm{n}=3$ in each group). (B) qPCR validation of six miRNAs in blood samples (fold changes, $\mathrm{n}=10, * P<0.05, * * P<0.01, * * * P<0.001$ ).

Abbreviations: miRNAs, microRNAs; qPCR, quantitative polymerase chain reaction. 
was significantly reduced by CSE stimulation (Figure 2B). Through bioinformatics prediction, we found that TLR-4 may be a target gene of miR-149-3p. The direct regulating effect of miR-149-3p on TLR-4 was verified by a dual luciferase assay. Reporter assay revealed that overexpression of miR-149-3p significantly suppressed the luciferase activity of wild TLR-4 $3^{\prime}$ untranslated region (UTR) plasmid in THP-1 cells $(P<0.05)$ without change in luciferase activity of mutant 3'UTR TLR-4 plasmid (Figure 2C and D). Moreover, CSE stimulation caused up-regulation of TLR-4 at both the mRNA and the protein levels (Figure 2E and F). The proteins downstream of TLR-4, mainly NF- $\mathrm{KB}$ p65, showed increased expressions in the CSE group. Consistent with these observations, immunofluorescence results showed similar changes in

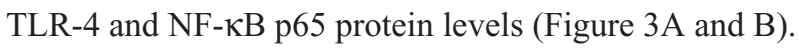

\section{Transfection of miR-149-3p inhibitors activated TLR-4/NF- $\kappa B$ p 65 signaling pathway}

To validate the down-regulation of miR-149-3p, we induced the activation of TLR-4/NF- $\mathrm{B}$ p65 signaling pathway.
miR-149-3p inhibitors were transfected into THP-1 cells. ELISA assay revealed that IL- $1 \beta$ and TNF- $\alpha$ significantly increased in the miR-149-3p inhibitor group compared with the NC group (Figure 4A). The mRNA level of TLR-4 was increased (Figure 4B), and protein levels of TLR-4 and NF- $\kappa$ B p65 were up-regulated in miR-149-3p inhibitor group compared to the NC group (Figure 4C). The immunofluorescence assay further confirmed that miR-149-3p inhibitors induced the activation of TLR-4/NF- $\mathrm{BB}$ p65 signaling pathway (Figure 5A and B).

\section{Transfection of miR-149-3p mimics reversed the expression of TLR-4 in CSE-stimulated THP-I cells}

To examine whether CSE affected the generation of inflammatory cytokines, we passed the THP-1 cells through miR149-3p. THP-1 cells were infected with miR-149-3p mimics after CSE stimulation treatment. As shown in Figure 6A, miR-149-3p was increased in the transfected miR-149-3p mimics group as compared with the NC group. The ELISA assay demonstrated a significant decrease in IL-1 $\beta$ and
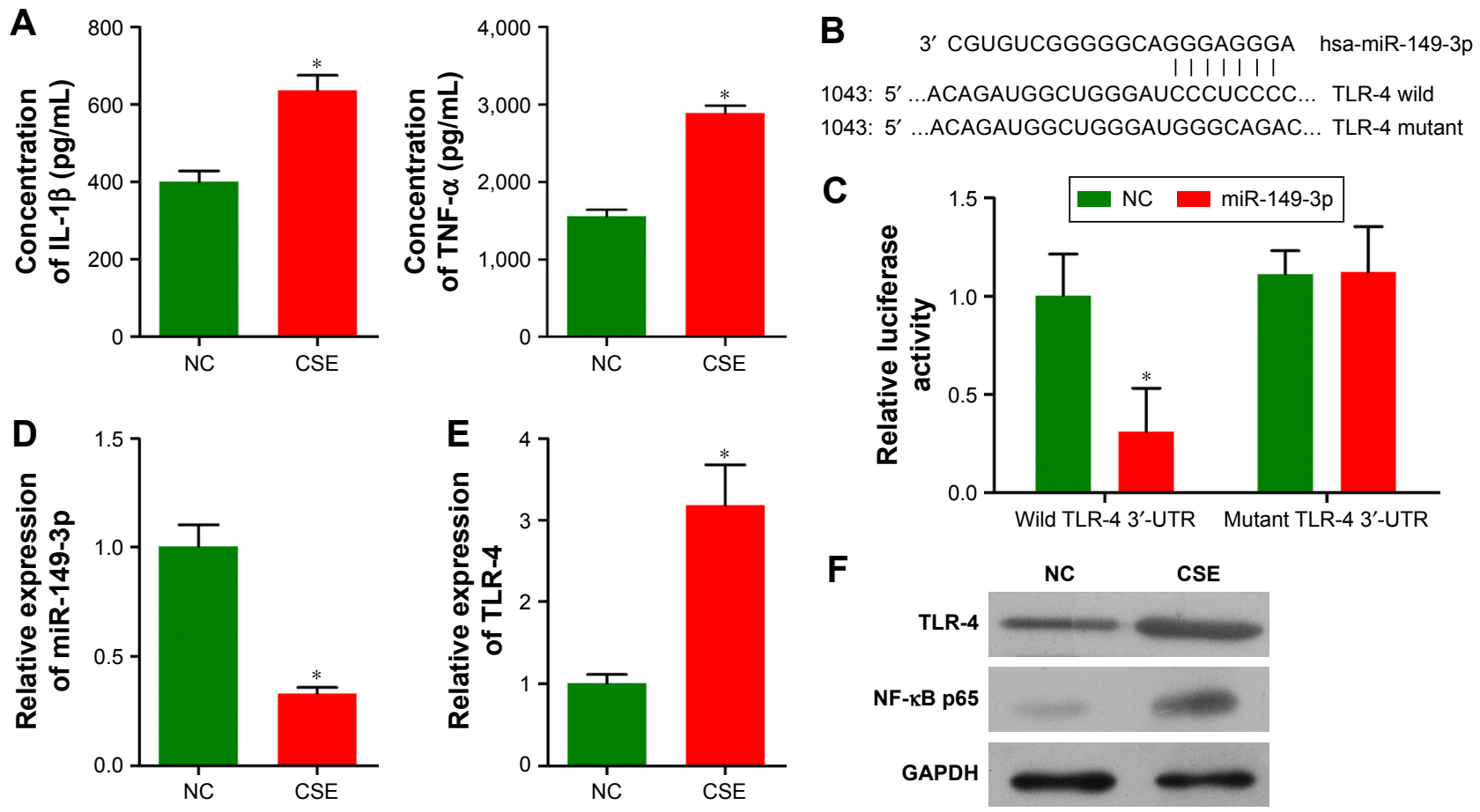

Figure 2 CSE induced down-regulation of miR-149-3p and up-regulation of TLR-4 in THP-I cells.

Notes: (A) ELISA results showed that concentration of IL-I $\beta$ and TNF- $\alpha$ significantly increased in CSE group compared with the NC group ( $n=3$, *P $<0.05$ ). (B and $\mathbf{C}$ ) The wild-type TLR-4 3'-UTR or mutant TLR-4 3'-UTR containing vector was co-transfected into THP-I cells with miR-I49-3p mimics. The luciferase activity was measured using the luciferase reporter gene assay $(* P<0.05)$. ( $(\mathbf{D}$ and $\mathbf{E})$ qPCR detected the expression levels of miR-I49-3P and TLR-4 ( $* P<0.05)$. ( $\mathbf{F})$ Western blot analysis of TLR-4 and NF- $\kappa \mathrm{B}$ p 65 proteins in THP-I cells.

Abbreviations: CSE, cigarette smoke extract; ELISA, enzyme-linked immunosorbent assay; IL, interleukin; NC, negative control; NF- $\kappa B$, nuclear factor $\kappa B$; qPCR, quantitative polymerase chain reaction; TLR-4, Toll-like receptor-4; TNF, tumor necrosis factor; UTR, untranslated region. 

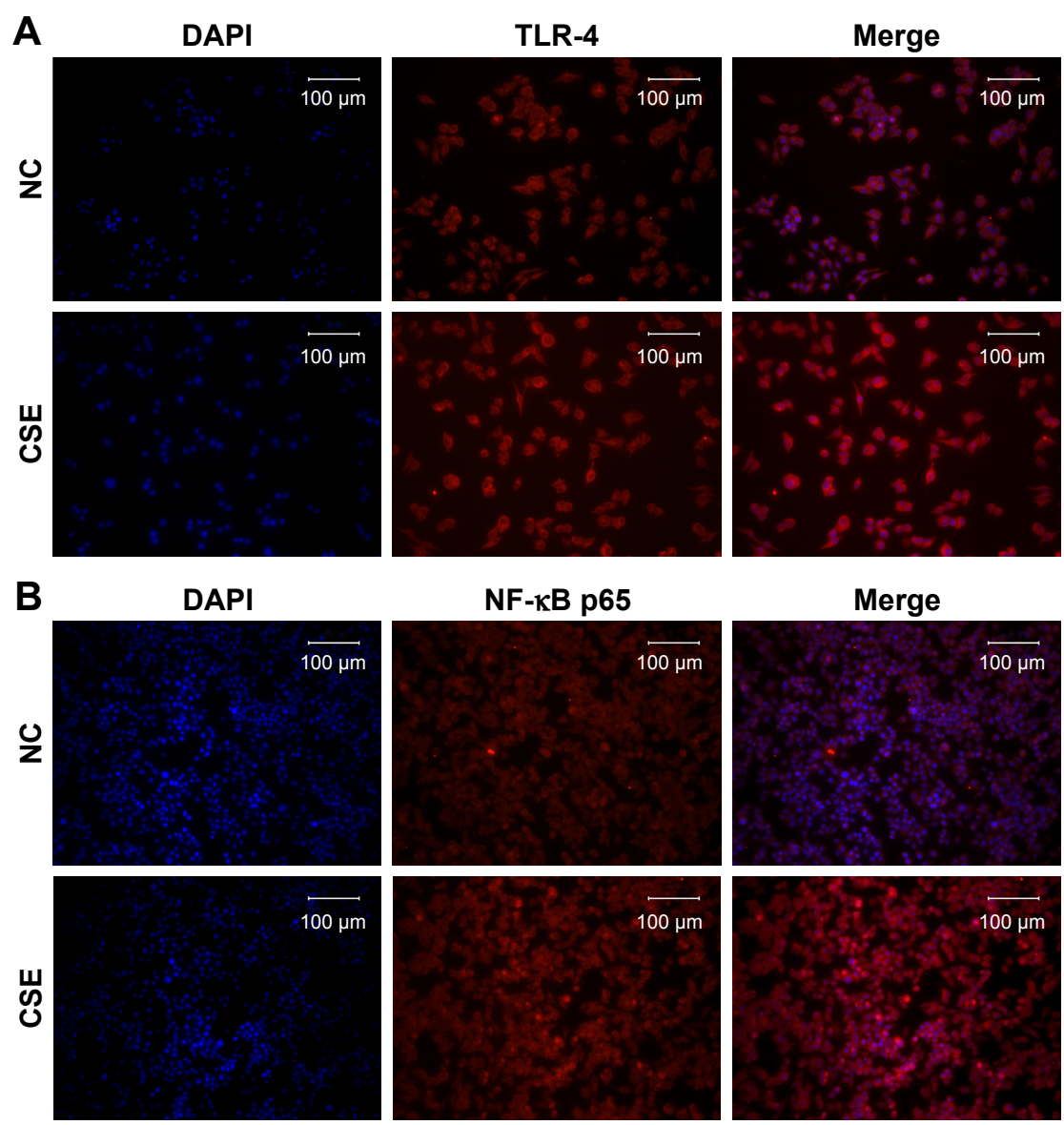

Figure 3 The protein expression level of TLR-4 (A) and NF-KB p65 (B) was detected by the immunofluorescence assay in THP-I cells. Notes: Merge: superimposed images of TLR-4 or NF-KB p65 in red and nuclei (DAPI) in blue, scale bars at $100 \mu \mathrm{m}$.

Abbreviations: CSE, cigarette smoke extract; DAPI, 4',6-diamidino-2-phenylindole; NC, negative control; NF-KB, nuclear factor KB; TLR-4, Toll-like receptor-4.

A

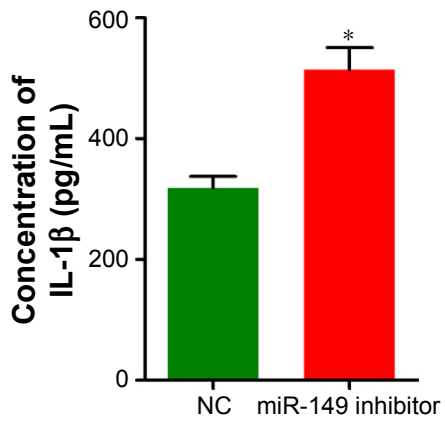

B

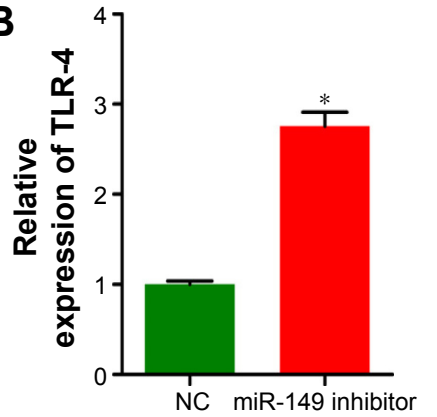

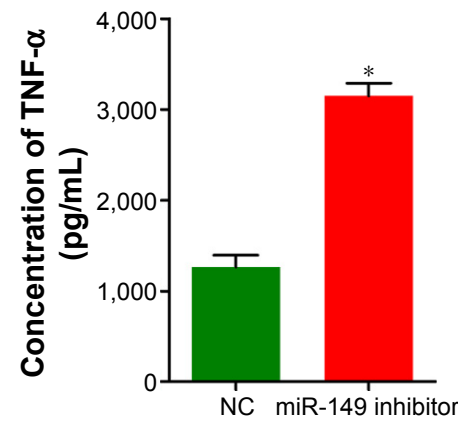

C

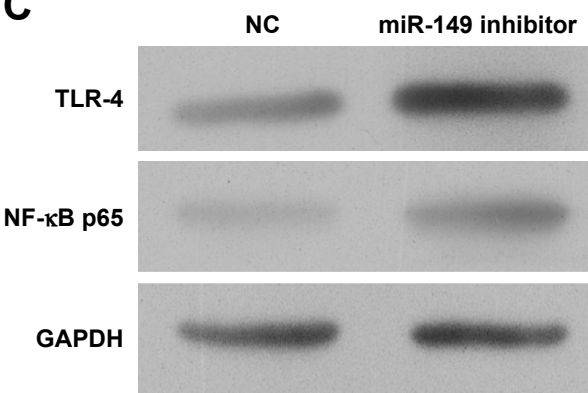

Figure 4 Inhibition of miR-149-3p activated the TLR-4/NF-kB p65 signaling pathway.

Notes: (A) ELISA showed that concentration of IL-I $\beta$ and TNF- $\alpha$ significantly increased in THP-I cells transfected with NC or miR-149-3p inhibitors ( $n=3$, *P<0.05). (B and C) qPCR and Western blot detected the expression level of TLR-4 and NF-KB p65 $(* P<0.05)$.

Abbreviations: ELISA, enzyme-linked immunosorbent assay; IL, interleukin; miR, microRNA; NC, negative control; NF- KB, nuclear factor KB; qPCR, quantitative polymerase chain reaction; TLR-4, Toll-like receptor-4; TNF, tumor necrosis factor. 
A
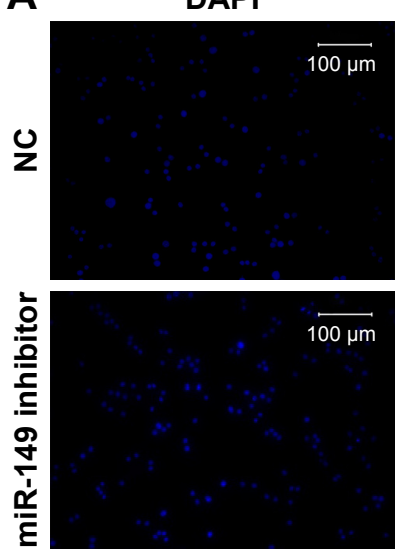

B
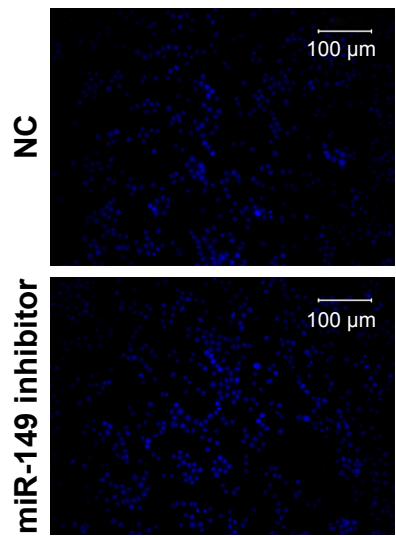

TLR-4
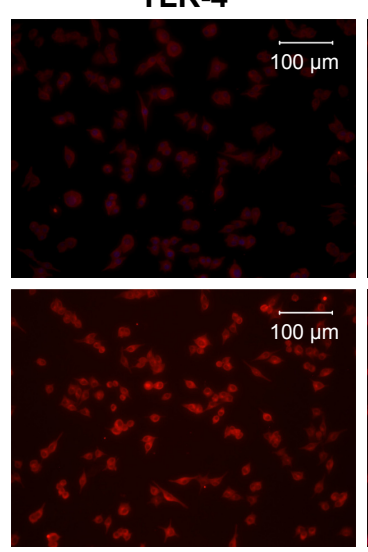

NF-kB p65
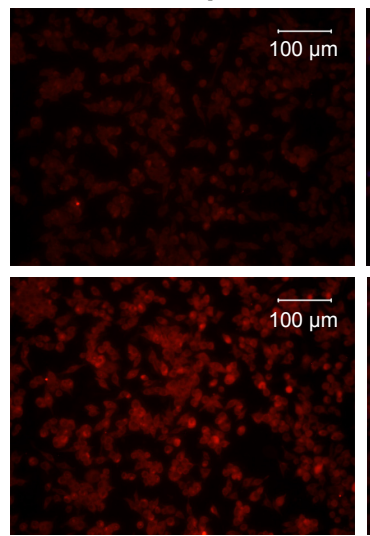

Merge
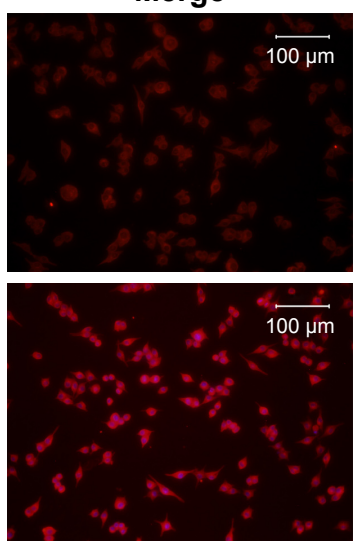

Merge
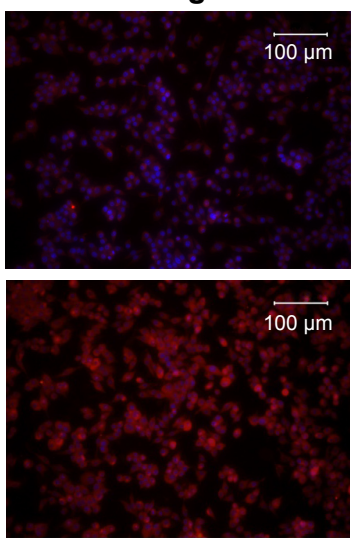

Figure 5 The protein expression level of TLR-4 (A) and NF-kB p65 (B) in THP-I cells transfected with NC or miR-I49-3p inhibitors was detected by the immunofluorescence assay.

Notes: Merge: superimposed images of TLR-4 or NF-KB p65 in red and nuclei (DAPI) in blue, scale bars at $100 \mu \mathrm{m}$.

Abbreviations: DAPI, 4',6-diamidino-2-phenylindole; NC, negative control; NF- $\kappa B$, nuclear factor $\kappa B$; TLR-4, Toll-like receptor-4.

TNF- $\alpha$ (Figure 6B) levels. The qPCR analysis showed that TLR-4 mRNA expression levels decreased in transfected miR-149-3p mimics group, and Western blots showed suppression of TLR-4/NF- $\mathrm{kB}$ p65 signaling pathway induced by miR-149-3p overexpression (Figure 6C and D). Images of immunofluorescence assay further confirmed this result (Figure $7 \mathrm{~A}$ and $\mathrm{B}$ ).

\section{Discussion}

We conducted a comprehensive analysis of miRNA in wholeblood samples from four different groups: non-smokers, smokers, catabatic period smokers with catabatic period COPD, and smokers with acute exacerbation period COPD. Our results revealed 56 differentially expressed miRNAs between the four groups. Validation with qPCR found that miR-3202, miR-26a-5p, miR-451b and miR-149-3p were significantly down-regulated in the three smoking groups compared with the non-smoking group. miR-96-5p expression was reduced in the blood of the normal smoking group compared to the normal non-smoking group, while in the two COPD groups, the expression of miR-96-5p was significantly higher. Besides, miR-301a-5p showed low expression levels only in the acute exacerbation period in smoking COPD patients. A comprehensive analysis of the miRNAs showed many of the same miRNAs that have been reported to play an important role in the occurrence and development of COPD. For example, our miRNA microarray showed that miR-145 was increased in blood samples in COPD patients compared with normal people, and Perry's study suggested that miR-145 negatively regulates proinflammatory cytokine release from airway smooth muscle cells in COPD by targeting SMAD3. ${ }^{16}$ The role of miR-26a has been investigated in the modulation of an inflammatory response in cultured microglia, and it was found that miR26a modulated inflammatory response induced by TLR-4 stimulation. ${ }^{32}$ In addition, another study found that miR-149 is down-regulated in osteoarthritic chondrocytes, and this decrease seems to be correlated to increased expression of pro-inflammatory cytokines such as TNF- $\alpha$, IL- $1 \beta$ and IL- $6{ }^{33}$ TNF- $\alpha$ induces the expression of genes associated 

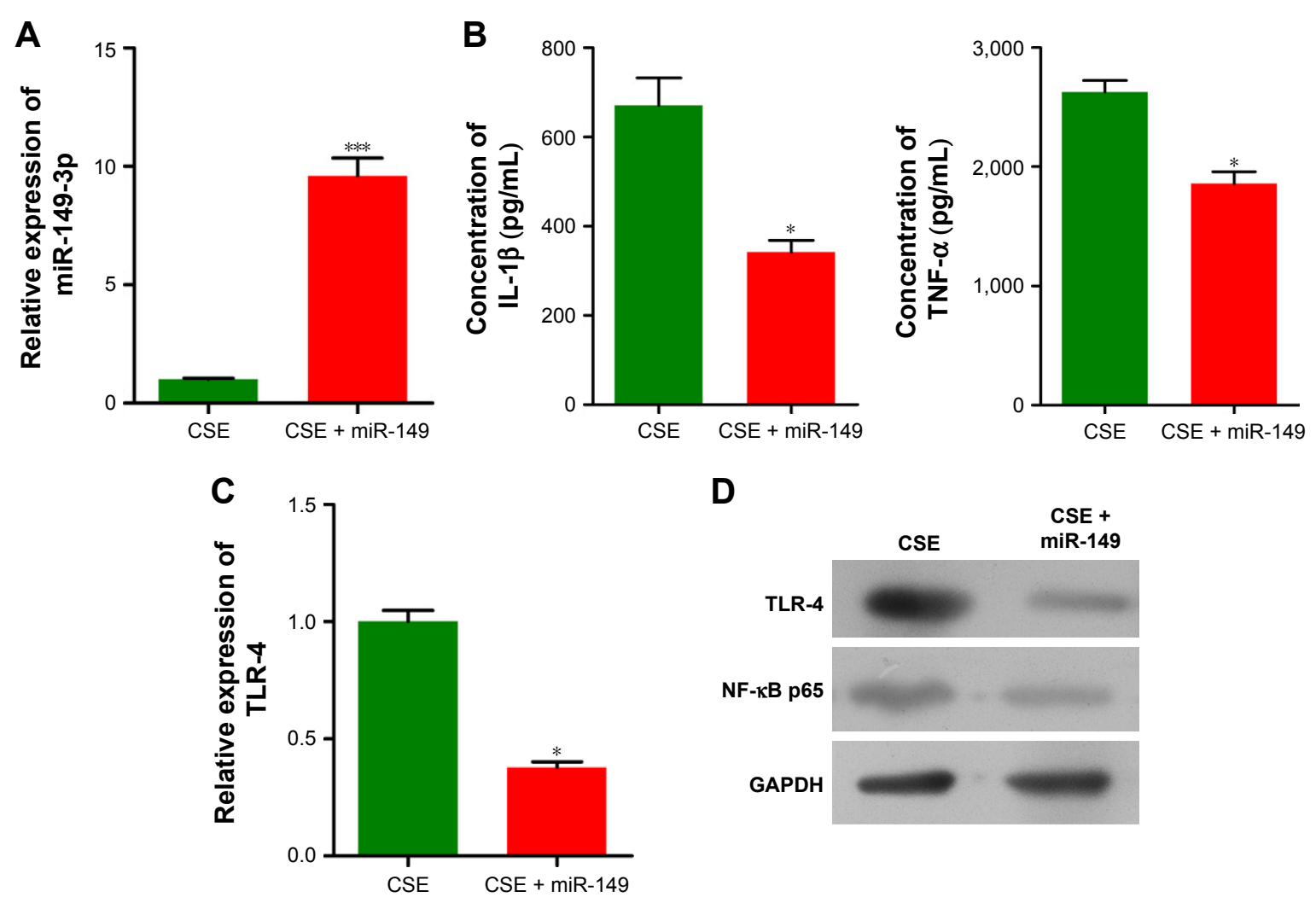

Figure 6 miR-149-3p overexpression reversed the effect of CSE on THP-I cells.

Notes: (A) qPCR detected the expression level of miR-I49-3p $(n=3$, ****P<0.00I). (B) ELISA showed that concentration of IL-I $\beta$ and TNF- $\alpha$ significantly decreased in miR-149-3p-overexpressed group compared with control group (only stimulated with CSE) $(* P<0.05)$. (C and $\mathbf{D})$ qPCR and Western blot detected the expression level of TLR-4 and NF- $\kappa B$ p $65(* P<0.05)$.

Abbreviations: CSE, cigarette smoke extract; ELISA, enzyme-linked immunosorbent assay; IL, interleukin; miR, microRNA; NF- $\kappa B$, nuclear factor $\kappa B$; qPCR, quantitative polymerase chain reaction; TLR-4, Toll-like receptor-4; TNF, tumor necrosis factor.

with endothelial dysfunction through p38MAPK-mediated down-regulation of miR-149. ${ }^{34}$ Furthermore, miR-149 is considered as a tumor suppressor to various tumors, such as renal cell carcinoma, ${ }^{35}$ colorectal carcinoma ${ }^{36}$ and hepatocellular carcinoma ${ }^{37}$ miR-149 is expressed in many tissues and thus plays different roles.

In this study, miR-149 was decreased in the smoking group compared with the non-smoking group. Down-regulation of miR-149 probably plays a key role in the pro-inflammatory cascade in lungs and bronchi. It has been shown that the C-containing genotypes of miR-149 rs2292832 are associated with a better overall survival of non-small-cell lung cancer, ${ }^{30}$ while another study reported that there was no association between miR-149 rs2292832 polymorphism with lung cancer risk in Chinese non-smoking females. ${ }^{38}$ Therefore, miR-149 expressed in lungs and bronchi may be affected by smoking. To explore this mechanism further, we predicted a target gene of miR-149 through 3'UTR sequence analysis on Targetscan, miRanda and DIANA-microT and performed simulated experiments in THP-1 cells. Simulation of CSE resulted in a decrease in miR-149 expression and an increase in the expression of its target gene, TLR-4. Furthermore, transfection of miR-149 inhibitors induces the up-regulation of TLR-4. Finally, miR-149 overexpression reverses the effect of CSE on THP-1 cells. We speculated that the miR-149 negatively regulates the inflammatory response in THP-1 cells by targeting TLR-4. Previous reports found that miR-149 might be a key player of the immune modulator for TLR/MyD88 signaling pathway in macrophages. ${ }^{39,40}$ TLR-4 is regulated by members of the let-7 miRNA family. The induction of let-7e expression could decrease the TLR- 4 expression on the cell surface of liver-derived cholangiocytes. ${ }^{41}$

Our study shows that the change in miR-149 expression caused the alteration of TLR-4 and NF- $\mathrm{\kappa B}$ p 65 protein levels. Many studies have investigated the expression of TLRs on both immune and epithelial cells in COPD. ${ }^{42-44}$ Nadigel et $\mathrm{a}^{45}$ demonstrated that $\mathrm{CD} 8^{+} \mathrm{T}$ cells exposed to cigarette smoke condensate increased TLR-4 and TLR-9 levels and also increased cytokine production. Another study found that acute cigarette exposure results in lipopolysaccharides-independent TLR4 activation, leading to IL-1 production and IL-1R1 signaling, which is crucial 

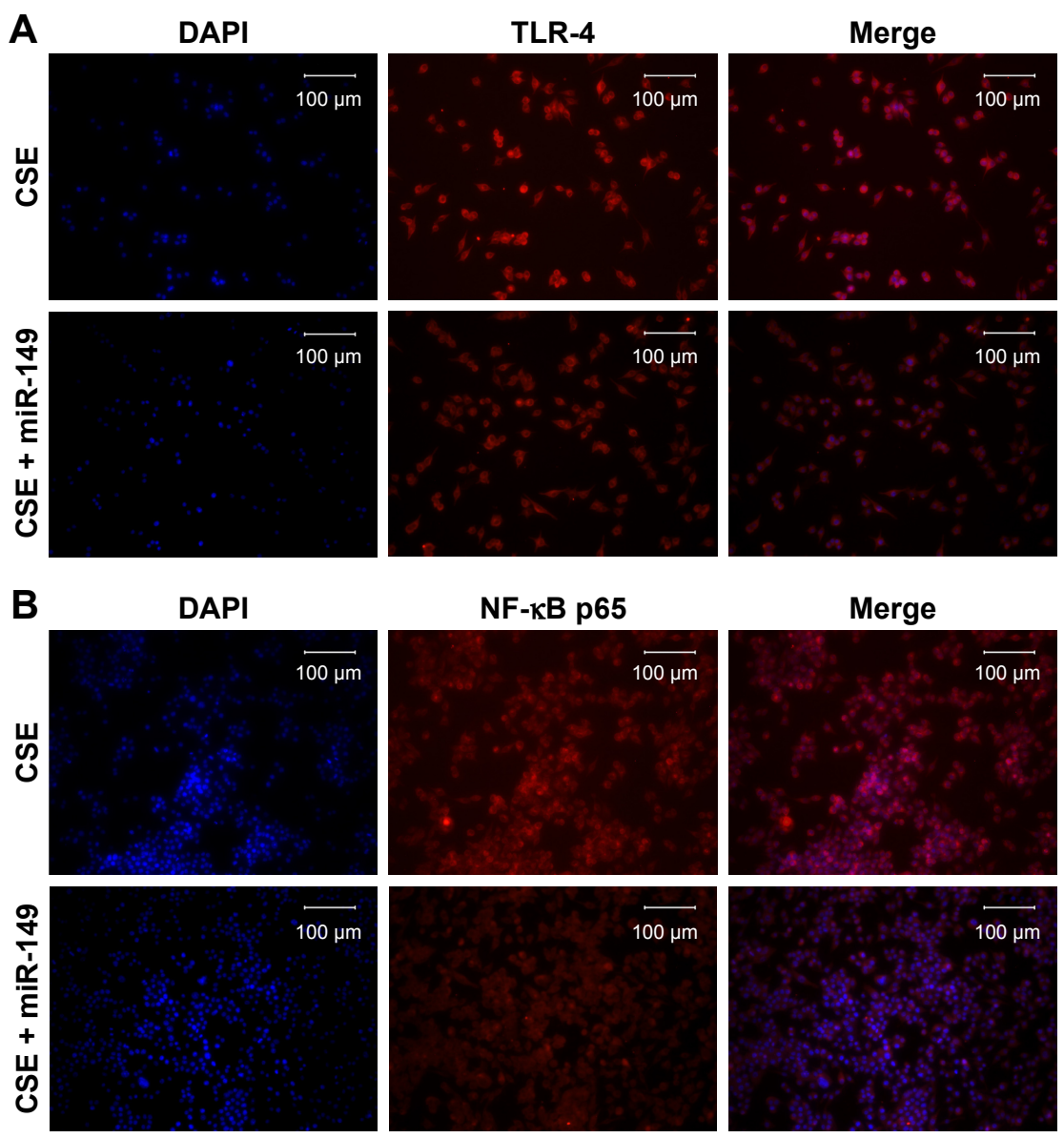

Figure 7 The protein expression level of TLR-4 (A) and NF-KB p65 (B) was detected by the immunofluorescence assay.

Notes: Merge: superimposed images of TLR-4 or NF-KB p65 in red and nuclei (DAPI) in blue, scale bars at $100 \mu \mathrm{m}$.

Abbreviations: CSE, cigarette smoke extract; DAPI, 4',6-diamidino-2-phenylindole; NF- $\kappa B$, nuclear factor $\kappa B$; TLR-4, Toll-like receptor-4.

for cigarette smoke-induced inflammation leading to COPD with emphysema. ${ }^{46}$ Geraghty et $\mathrm{al}^{47}$ found that mice exposed to acute levels of cigarette smoke exhibited increased TLR-4 expression and TLR-4 signaling, through MyD88 and IRAK1, which play a predominant role in matrix metalloproteinase 1 (MMP-1) induction. We observed TLR-4, NF- $\mathrm{B}$ p65, IL-1 $\beta$ and TNF- $\alpha$ levels after miR-149 overexpression or knockdown. Results revealed that miR-149 suppresses inflammation through targeting TLR-4.

\section{Conclusion}

Our study demonstrated that smoking can induce differential expression of circulating miRNAs, such as down-regulation of miR-149-3p. Reducing miR-149-3p may increase the inflammatory response in COPD patients through the regulation of TLR-4/NF- $\kappa \mathrm{B}$ signaling.

\section{Acknowledgments}

This study was supported by grants from the National Natural Science Foundation of China (No 81402991) and
Yunnan Provincial Science and Technology Department (No 20141A033).

\section{Author contributions}

Conceived and designed the paper: WS, JL and YZ. Collected the data: WS, JL, GZ, MF, GS and YZ. Analyzed the data: WS and JL. Wrote the paper: WS, ZW and YZ. All authors read and approved the final manuscript. All authors contributed toward data analysis, drafting and revising the paper and agreed to be accountable for all aspects of the work.

\section{Disclosure}

The authors report no conflicts of interest in this work.

\section{References}

1. Vestbo J, Hurd SS, Agustí AG, et al. Global strategy for the diagnosis, management, and prevention of chronic obstructive pulmonary disease: GOLD executive summary. Am J Respir Crit Care Med. 2007;187(176): $532-555$.

2. Diaz-Guzman E, Mannino DM. Epidemiology and prevalence of chronic obstructive pulmonary disease. Clin Chest Med. 2014;35(1): $7-16$. 
3. Balasubramanian VP, Varkey B. Chronic obstructive pulmonary disease: effects beyond the lungs. Curr Opin Pulm Med. 2006;12(2):106-112.

4. Wang J, Satya S, Kuhle JW. Tobacco smoking and environmental risk factors for chronic obstructive pulmonary disease. Clin Chest Med.2014; 35(1):17-27.

5. Eisner MD, Anthonisen N, Coultas D, et al. An official American Thoracic Society public policy statement: novel risk factors and the global burden of chronic obstructive pulmonary disease. Am J Respir Crit Care Med. 2010;182(5):693-718.

6. National Center for Chronic Disease Prevention and Health Promotion (US) Office on Smoking and Health. The Health Consequences of Smoking - 50 Years of Progress: A Report of the Surgeon General. Atlanta, GA: Centers for Disease Control and Prevention (US); 2014.

7. U.S. Department of Health and Human Services. The Health Consequences of Smoking: A Report of the Surgeon General. Atlanta, GA: U.S. Department of Health and Human Services, Centers for Disease Control and Prevention, National Center for Chronic Disease Prevention and Health Promotion, Office on Smoking and Health. 2004.

8. Moritsugu KP. The 2006 Report of the Surgeon General: the health consequences of involuntary exposure to tobacco smoke. American Journal of Preventive Medicine. 2007;32(6):542-543.

9. Ezzati M, Lopez AD. Estimates of global mortality attributable to smoking in 2000. Lancet. 2003;362(9387):847-852.

10. Yin $P$, Jiang CQ, Cheng KK, et al. Passive smoking exposure and risk of COPD among adults in China: the Guangzhou Biobank Cohort Study. Lancet. 2007;370(9589):751-757.

11. Sezer H, Akkurt İ, Guler N, Marakoğlu K, Berk S. A case-control study on the effect of exposure to different substances on the development of COPD. Ann Epidemiol. 2006;16(1):59-62.

12. Bartel DP. MicroRNA target recognition and regulatory functions. Cell. 2009;136(2):215-233.

13. Izzotti A, Calin GA, Arrigo P, Steele VE, Croce CM, De Flora S. Downregulation of microRNA expression in the lungs of rats exposed to cigarette smoke. FASEB J. 2009;23(3):806-812.

14. Izzotti A, Calin GA, Steele VE, Croce CM, De Flora S. Relationships of microRNA expression in mouse lung with age and exposure to cigarette smoke and light. FASEB J. 2009;23(23):3243-3250.

15. Ezzie ME, Crawford M, Cho JH, et al. Gene expression networks in COPD: microRNA and mRNA regulation. Thorax. 2011;67(2):122-131.

16. O'Leary L, Sevinç K, Papazoglou IM, et al. Airway smooth muscle inflammation is regulated by microRNA-145 in COPD. FEBS Lett. 2016;590(9):1324-1334.

17. O’Leary L, Tildy B, Papazoglou I, Adcock I, Fan C, Perry M. miRNA$145 \&$ SMAD3 expression in patients with COPD. Eur Respir J. 2014;44:3342.

18. Zago M, Souza ARD, Hecht E, et al. The NF-кB family member RelB regulates microRNA miR-146a to suppress cigarette smoke-induced COX-2 protein expression in lung fibroblasts. Toxicol Lett. 2014;226(2):107-116.

19. Soeda S, Ohyashiki JH, Ohtsuki K, Umezu T, Setoguchi Y, Ohyashiki K. Clinical relevance of plasma miR-106b levels in patients with chronic obstructive pulmonary disease. Int J Mol Med. 2013;31(3): $533-539$.

20. Leuenberger C, Schuoler C, Mignan C, et al. microRNA-223 suppresses histone deacetylase 2 in chronic obstructive pulmonary disease. Eur Respir J. 2015;46(suppl):59.

21. Leidinger $P$, Keller A, Borries A, et al. Specific peripheral miRNA profiles for distinguishing lung cancer from COPD. Lung Cancer. 2011;74(1): 41-47.

22. Heneghan HM, Miller N, Lowery AJ, Sweeney KJ, Newell J, Kerin MJ. Circulating microRNAs as novel minimally invasive biomarkers for breast cancer. Ann Surg. 2010;251(3):499-505.

23. Tsujiura M, Ichikawa DS, Shiozaki A, et al. Circulating microRNAs in plasma of patients with gastric cancers. Br J Cancer. 2010; 102(7):1174-1179.
24. Ke Z, Zhang CY. Circulating microRNAs: a novel class of biomarkers to diagnose and monitor human cancers. Med Res Rev. 2012;32(2): 326-348.

25. Fichtlscherer S, De RS, Fox H, et al. Circulating microRNAs in patients with coronary artery disease. Circ Res. 2010;107(5):677-684.

26. Lewis PJS, Dear J, Platt V, et al. Circulating microRNAs as potential markers of human drug-induced liver injury. Hepatology. 2011;54(5): 1767-1776.

27. Donaldson A, Lewis A, Natanek S, Man W, Kemp P, Polkey M. Investigating circulating microRNAs as potential biomarkers of quadriceps weakness in COPD. Eur Respir J. 2011;38:206.

28. Donaldson AVJ, Lewis A, Natanek A, Man WD, Kemp P, Polkey MI. S49 Increased skeletal muscle-specific microRNA-1 in the blood of COPD patients. Thorax. 2011;66(suppl 4):A25-A25.

29. Donaldson A, Natanek SA, Lewis A, et al. Increased skeletal musclespecific microRNA in the blood of patients with COPD. Thorax. 2013;68(12):1140-1149.

30. Lingzi X, Zhihua Y, Xuelian L, et al. Genetic variants in microRNAs predict non-small cell lung cancer prognosis in Chinese female population in a prospective cohort study. Oncotarget. Epub 2016 Nov 4.

31. Krimmer DI, Burgess JK, Wooi TK, Black JL, Oliver BG. Matrix proteins from smoke-exposed fibroblasts are pro-proliferative. $\mathrm{Am} \mathrm{J}$ Respir Cell Mol Biol. 2011;46(1):34-39.

32. Kumar A, Bhatia HS, de Oliveira AC, Fiebich BL. microRNA-26a modulates inflammatory response induced by toll-like receptor 4 stimulation in microglia. J Neurochem. 2015;135(6):1189-1202.

33. Santini P, Politi L, Vedova PD, Scandurra R, Scottod AA. The inflammatory circuitry of miR-149 as a pathological mechanism in osteoarthritis. Rheumatol Int. 2014;34(5):711-716.

34. Palmieri D, Capponi S, Geroldi A, Mura M, Mandich P, Palombo D. TNF $\alpha$ induces the expression of genes associated with endothelial dysfunction through p38MAPK-mediated down-regulation of miR-149. Biochem Biophys Res Commun. 2013;443(1):246-251.

35. Jin L, Li Y, Liu J, et al. Tumor suppressor miR-149-5p is associated with cellular migration, proliferation and apoptosis in renal cell carcinoma. Mol Med Rep. 2016;13(6):5386-5392.

36. Liu X, Xie T, Mao X, Xue L, Chu X, Chen L. MicroRNA-149 increases the sensitivity of colorectal cancer cells to 5-fluorouracil by targeting forkhead box transcription factor FOXM1. Cell Physiol Biochem. 2016;39(2):617-629.

37. Lin L, Zhang YD, Chen ZY, Chen Y, Ren CP. The clinicopathological significance of miR-149 and PARP-2 in hepatocellular carcinoma and their roles in chemo/radiotherapy. Tumor Biol. 2016;37(9): 12339-12346.

38. Li H, Ren Y, Xia L, et al. Association of microRNA-149 polymorphism with lung cancer risk in Chinese non-smoking female: a case-control study. PLoS One. 2016;11(9):e0163626.

39. Xu G, Zhang Z, Xing Y, et al. MicroRNA-149 negatively regulates TLR-triggered inflammatory response in macrophages by targeting MyD88. J Cell Biochem. 2014;115(5):919-927.

40. Schnitger AKD, Machova A, Mueller RU, et al. Listeria monocytogenes infection in macrophages induces vacuolar-dependent host miRNA response. PLoS One. 2004;510(5):502-513.

41. Chen XM, Splinter PL, O’Hara SP, Larusso NF. A cellular microRNA, let-7i, regulates Toll-like receptor 4 expression and contributes to cholangiocyte immune responses against Cryptosporidium parvum infection. J Biol Chem. 2007;282(39):28929-28938.

42. Pons J, Sauleda J, Regueiro V, et al. Expression of Toll-like receptor 2 is up-regulated in monocytes from patients with chronic obstructive pulmonary disease. Respir Res. 2006;7(1):64

43. Macredmond RE, Greene CM, Dorscheid DR, Mcelvaney NG, O'Neill SJ. Epithelial expression of TLR4 is modulated in COPD and by steroids, salmeterol and cigarette smoke. Respir Res. 2007;8(1):84. 
44. Zuany-Amorim C, Hastewell J, Walker C. Toll-like receptors as potential therapeutic targets for multiple diseases. Nat Rev Drug Discov. 2002;1(10):797-807.

45. Nadigel J, Préfontaine D, Baglole CJ, et al. Cigarette smoke increases TLR4 and TLR9 expression and induces cytokine production from CD8+ $\mathrm{T}$ cells in chronic obstructive pulmonary disease. Respir Res. 2011; 12(10):1214-1216.
46. Doz E, Noulin N, Boichot E, et al. Cigarette smoke-induced pulmonary inflammation is TLR4/MyD88 and IL-1R1/MyD88 signaling dependent. J Immunol. 2008;180(2):1169-1178.

47. Geraghty P, Dabo AJ, D'Armiento J. TLR4 protein contributes to cigarette smoke-induced matrix metalloproteinase-1 (MMP-1) expression in chronic obstructive pulmonary disease. J Biol Chem. 2011; 286(34):30211-30218.

International Journal of COPD

\section{Publish your work in this journal}

The International Journal of COPD is an international, peer-reviewed journal of therapeutics and pharmacology focusing on concise rapid reporting of clinical studies and reviews in COPD. Special focus is given to the pathophysiological processes underlying the disease, intervention programs, patient focused education, and self management protocols.
Dovepress

This journal is indexed on PubMed Central, MedLine and CAS. The manuscript management system is completely online and includes a very quick and fair peer-review system, which is all easy to use. Visit $\mathrm{http}: / / \mathrm{www}$.dovepress.com/testimonials.php to read real quotes from published authors.

Submit your manuscript here: http://www.dovepress.com/international-journal-of-chronic-obstructive-pulmonary-disease-journal 